\title{
Standard Quality and Antibacterial Activity Tests of Clove Oil in Solid Soap Production Against Staphylococcus aureus, Staphylococcus epidermidis and Escherichia coli
}

\author{
SRI HANDAYANI ${ }^{1 *}$, SUSILA KRISTIANINGRUM ${ }^{1}$ and ANNA RAKHMAWATI ${ }^{2}$ \\ 'Department of Chemistry Education, Faculty of Mathematics and Natural Sciences, \\ Yogyakarta State University, Indonesia. \\ ${ }^{2}$ Department of Biology Education Faculty of Mathematics and Natural Sciences \\ Yogyakarta State University, Indonesia. \\ *Coresponding author E-mail: handayani@ uny.ac.id \\ http://dx.doi.org/10.13005/ojc/340524
}

(Received: August 24, 2018; Accepted: October 07, 2018)

\begin{abstract}
This study aims to determine the quality and antibacterial activity of clove oil-solid soap production against three kinds of bacteria. Soap production was initiated by saponification reaction of olive, palm, coconut and castor oils with sodium hydroxide. Clove oil (2 and $3 \%$ ) was added to the saponizing reaction as an antibacterial agent. Quality test of solid-soap was based on Indonesian National Standard (INS) 2016. The in vitro antibacterial activity against Staphylococcus aureus ATCC 25923, Staphylococcus epidermidis FNCC 0048, and Escherichia coli ATCC 11229 in clove oil-solid soap was investigated using the Kirby-Bauer Diffusion method. The results show that quality test of all the solid soaps have fulfilled the INS requirements and performs inhibition against all bacteria. It suggests that clove oil is potentially used as an antibacterial agent in the manufacture of bath soap.
\end{abstract}

Keywords: Antibacterial activity, Clove oil, Soap quality.

\section{INTRODUCTION}

Solid soap is a skin cleanser made of saponification or neutralization process of fat, oil, wax, rosin or acid with organic or inorganic bases without causing irritation ${ }^{1}$. The soap can be produced using alkali and one kind one kind of vegetable oil or a mixture of several vegetable oils ${ }^{2}$. Antibacterial soap is a soap that contains antibacterial chemical ${ }^{3}$ and it is triclosan which is commonly used as antibacterial agent in household products including soap ${ }^{4}$. The researches reported in 1999-2000 showed that $45 \%$ of the soap circulating in the United States contained triclosan or triclocarban ${ }^{5}$. Meanwhile, data on the advantages of using antibacterial agents are still limited and suspected to cause resistance. Therefore, to reduce the risk of health problems, antibacterial agents of natural ingredients are needed for the manufacture of soap.

The types of vegetable oils that have been reported to be used for soap production are 
palm oil and palm kernel oil ${ }^{6}$, sesame oil ${ }^{7}$, as well as waste cooking oil ${ }^{8}$. In addition, virgin coconut oil (VCO) also has the potential for soap-making materials because it has biological activity as an anti-inflamatory, analgesic, and anti-pyrectic agents ${ }^{9}$. On the other hand, soaps made of palm oil and palm kernel oil contain $\mathrm{C}_{16}-\mathrm{C}_{18}$ and $\mathrm{C}_{12}-\mathrm{C}_{14}$ fatty acids which are essential for detergency, saponification, and soap functions as cleaning agent ${ }^{6}$. Castor oil is highly versatile in the chemical industry because of its main content of risinoleic acid ${ }^{10}$. It is mainly used as the basic ingredient in the drug industry ${ }^{11}$, and its content of ricinoleic acid has a biological activity as an anti-inflammatory agent ${ }^{12}$. Bath soaps made of castor oil have chemical physico properties which include water content and bath-volatile substances ranging from 13.470 to $14.810 \%$, fatty acids (77.615$83.710 \%)$, unsaturated fraction content (7.385$7.710 \%)$, insoluble matter in alcohol (0.565-0.765\%), free alkali as $\mathrm{NaOH}(0.020-0.045 \%)$, degree of acidity $(\mathrm{pH})(9.375-9.815 \%)$, emulsion stability (83.435-85.520\%), foam stability (83.350-88.540\%) and hardness of the soap (3.135-4.775 mm/g.sec ${ }^{13}$. Soaps made of olive oil have proven to be of high quality ${ }^{14}$. On the other hand, olive oil contains many unsaturated fatty acids as well as tocopherols and phenolic compounds to be potential as antioxidant ${ }^{15}$ and anticancer ${ }^{16}$ agents.

In addition to have cleaning and perfuming agents, soap can also be an antibacterial product by adding certain substances such as essential oils. Basil is one of the essential oils used as an additive substance for antibacterial agent in soap making ${ }^{17}$. Another potentially natural substance for antibacterial agent is clove oil ${ }^{18,19}$. Clove oil which has the main content of eugenol (78\%) and caryophyllene (13\%), has been used as anesthesia and analgesics in in the field of dentistry. Eugenol is known as an antioxidant and antiinflammatory agents $^{20}$, while clove oil has a cytotoxic effect at $0.03 \%$ concentration ${ }^{21}$. For this reason, the main idea in this research is to produce a natural bath soap using the mixture of several vegetable oils including coconut oil, palm oil, castor oil, and olive oil, with an addition of clove oil as the antibacterial agent.

The quality of the soap was tested based on the INS 2016 involving the analysis of water content, chloride content, insoluble matter in ethanol, free alkali, total fat, and unsaponifiable matter ${ }^{1}$. This research, then, aimed to examine the quality and antibacterial activity of clove oil in the natural bath-soap. The antibacterial test was performed using the Kirby-Bauer diffusion method against Staphylococcus aureus, Staphylococcus Epidermidis and Escherischia coli bacteria ${ }^{22,23}$.

\section{MATERIALS AND METHODS}

Virgin coconut oil, palm oil, olive oil, castor oil, and clove oil were purchased from local market in Yogyakarta, Indonesia. All of the chemical substances were from E-merck. Staphylococcus aureus ATCC 25923, Staphylococcus epidermidis FNCC 0048, Escherichia coli ATCC 11229, Nutrient Broth, and chloramphenicol were used for the antibacterial activity test. Gas Chromatography Mass Spectroscopy (GCMS) were recorded on an GC17A MSQP 5000 Shimadzu. Statictical analysis for the data of antibacterial experiments were carried out with IBM SPSS Statistics version ${ }^{21}$.

\section{Saponification reaction}

The soap was made from saponification reaction of vegetable oils mixed with $50 \mathrm{~g} \mathrm{NaOH}$ in $135 \mathrm{~mL}$ of aquadest using the cold process method. The vegetable oils used were $121 \mathrm{~g}$ of olive oil, 106.5 $\mathrm{g}$ of palm oil, $106.5 \mathrm{~g}$ of coconut oil and $15 \mathrm{~g}$ of castor oil. Stirring was done until the soap was perfectly formed at room temperature. Clove oil ( $2 \%$ and $3 \%$ ) was then added to the mixture, followed by evenly stirring until it was perfectly mixed. The mixture was then poured into the mold and allowed to stand for two days until it turned solid. Once becoming solid, the soap was removed from the mold and then the curing process began up to three to four weeks. Afterwards, the soap would be ready for both quality test and antibacterial activity test.

\section{Quality test}

The soap was tested for the quality of water content, total fat, ethanol insoluble matter, free alkali (or free fat), chloride and and unsaponifiable matter. The test procedure was in accordance with INS $2016^{1}$. The formula used to determine the value of unsaponifiable matter is as follows: 
unsaponifiable matter $=\left(b 1-\frac{v \times M}{10000}-b 2\right) \times \frac{100}{b o}$

bo $=$ test sample weight $(\mathrm{g})$

$\mathrm{b} 1=$ the first extract weight $(\mathrm{g})$

b2 $=$ the second extract weight $(\mathrm{g})$

$\mathrm{M}=$ the relative average of molar weight of fatty acid in the soap.

$\mathrm{V}=$ volume of the standard solution $\mathrm{KOH} 0.1 \mathrm{~N}$ used in the acidity calculation in the first extraction $(\mathrm{mL})$.

The fatty acid analysis in the oils used to determine the average molecular weight of vegetable oils $(\mathrm{M})$ were carried out by means of transesterification using $\mathrm{BF}_{3}$-methanol. The transesterification reaction began when $\mathrm{NaOH}$ was added to $1 \mathrm{~mL}$ of oil and then spin for 1 minute. Furthermore, $\mathrm{BF}_{3}$-methanolate was added to the mixture and the reaction was completed using vortex. The organic layer was then extracted using hexane, being ready to be injected into the GC-MS device.

\section{Antibacterial test}

The antibacterial test was performed by modifying the procedure of Cavalieri et al., ${ }^{22}$ and Balouiri et al., ${ }^{23}$. The Kirby-Bauer diffusion method was performed against Staphylococcus aureus ATCC 25923 bacterium, Staphylococcus epidermidis FNCC 0048, and Escherichia coli ATCC 11229. Bacterial isolates were grown on Nutrient Broth (NB) medium during the $24 \mathrm{~h}$ incubation period at $37^{\circ} \mathrm{C}$. The bacterial suspension was inoculated on Mueller Hinton Agar (MHA) plate medium according to the spread plate method. Blank paper discs were dipped for $5 \mathrm{~min}$. on various treatments, and then placed on the surface of MHA plate. The treatments were performed by the additions of $2 \%$ and $3 \%$ clove oils soap with the concentration of $2.5 \%, 5 \%$, $7.5 \%$, and $10 \%$ for each. The positive control was chloramphenicol (10 ppm) and the negative control was aquadest only. The plates were incubated for $48 \mathrm{~h}$ at $37^{\circ} \mathrm{C}$ and the diameter of the clear zone was measured using the sliding term at $6,12,24,30,36$, 42 , and 48 hours.

\section{RESULTS AND DISCUSSION}

\section{Quality test of natural soap}

There were a series of quality tests on the soap involving analyzing the water content, total fat, insoluble matter in ethanol, free alkali (or free fatty acid) and unsaponified fat residue. Total fat is the water-insoluble fat obtained from the decomposition of soap with mineral acids under particular conditions, including unsaponifiable matter, glycerides, and rosin acids in soap. Free alkali refers to the remaining unreacted base. Unsaponified fats or oils are those that do not react in the saponification reaction.

One of the soap quality standards required in the INS is the amount of the unsaponified residual fat content. The value set as the standard of soap quality for unsaponifiable matter is a maximum of $0.5 \%$. The average weight of the four kinds of vegetable oils (M) was analyzed using GC-MS. Chromatogram of vegetable oils were presented in Fig. 1-4, and the average weight of the four kinds of vegetable oils on soap (M) was presented in Table 1.

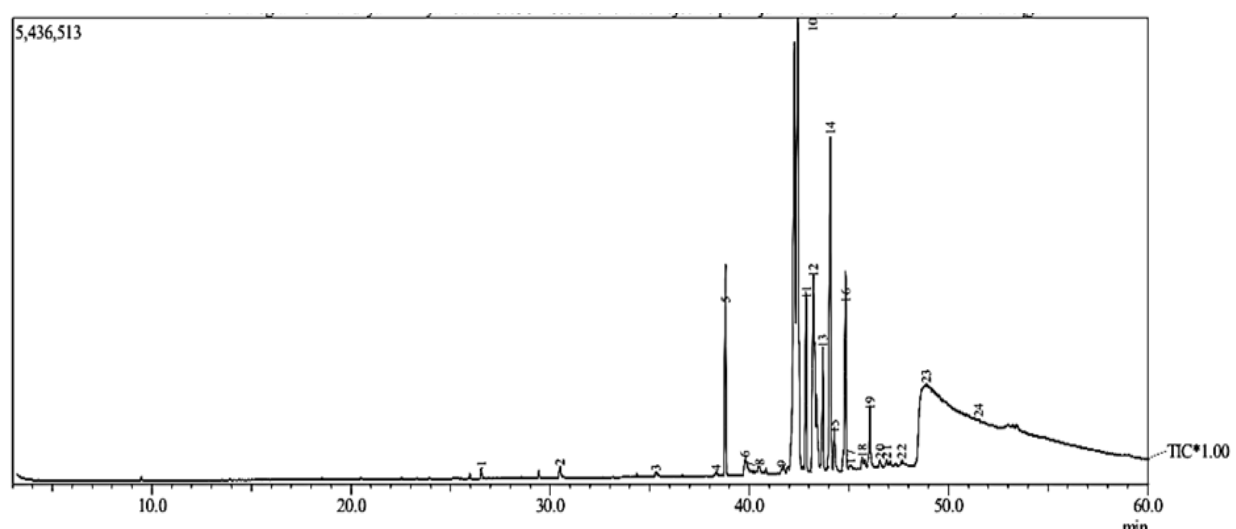

Fig. 1. Chromatogram of castor oil 


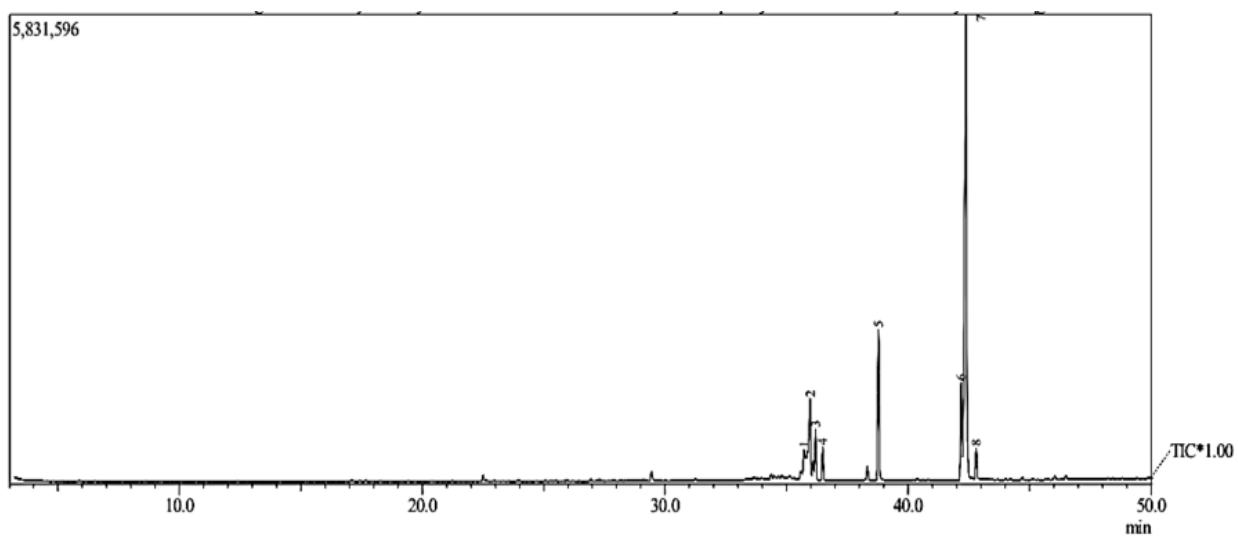

Fig. 2. Chromatogram of olive oil

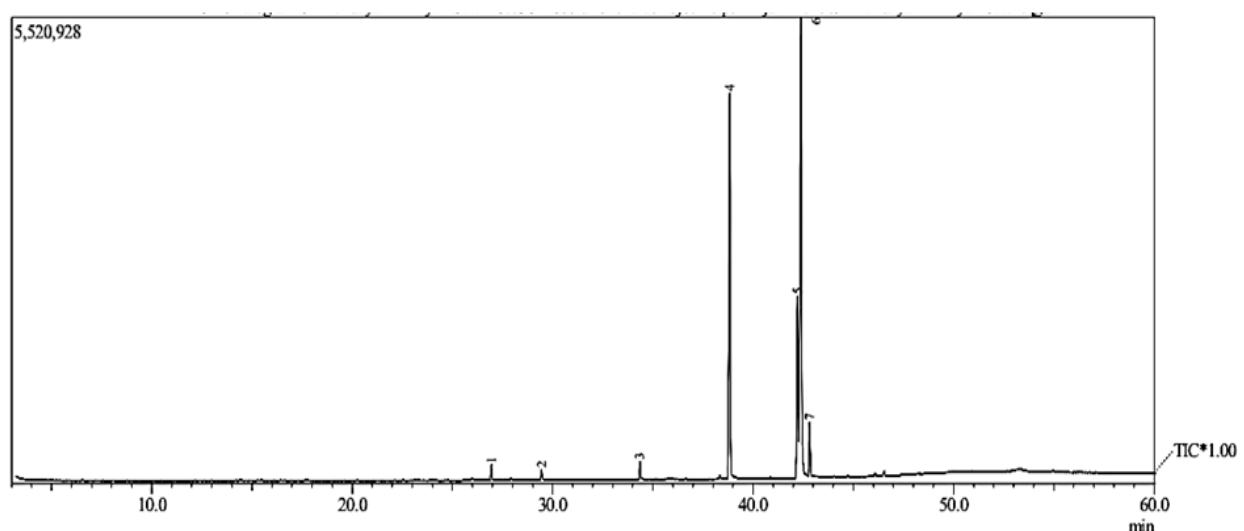

Fig. 3. Chromatogram of palm oil

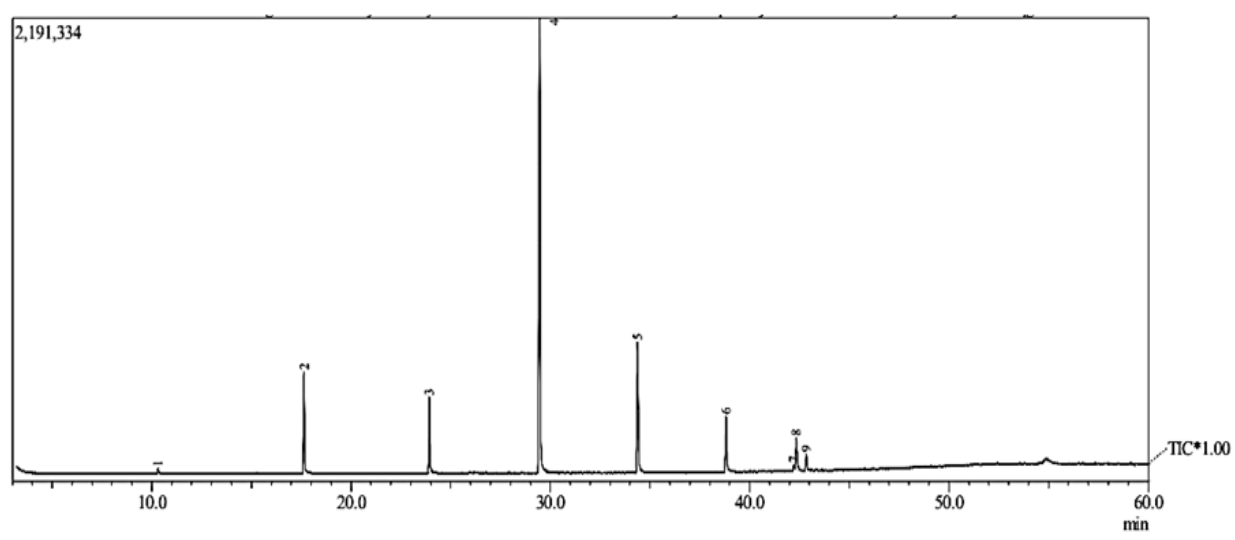

Fig. 4. Chromatogram of virgin coconut oil

Table 1: The average molecular weight of vegetable oils in the soap substances

\begin{tabular}{|c|c|c|c|c|c|c|c|c|c|c|}
\hline \multirow[b]{2}{*}{ Olis } & \multirow[b]{2}{*}{$\mathrm{C}_{8}$} & \multicolumn{8}{|c|}{ Molecular weight $\mathrm{x}$ Content } & \multirow[t]{2}{*}{ Total } \\
\hline & & $C_{10}$ & $C_{16}$ & $C_{16: 2}$ & $\mathrm{C}_{18}$ & $\mathrm{C}_{18: 1}$ & $\mathrm{C}_{18: 2}$ & $\mathrm{C}_{18} \mathrm{O}_{3}$ & $\mathrm{C}_{20}$ & \\
\hline VCO & 13.55 & 102.55 & - & - & 77.95 & 11.56 & - & - & - & 198.68 \\
\hline Palm & & - & 84.61 & 35.28 & 12,04 & 127.46 & - & - & - & 259.39 \\
\hline Olive & & - & - & 22.93 & 6.90 & 153.07 & - & - & 39.03 & 221.93 \\
\hline Castor & & - & 9.91 & & $\begin{array}{c}10.11 \\
M=\end{array}$ & - & & 119.42 & 89.10 & $\begin{array}{c}228.54 \\
227.135\end{array}$ \\
\hline
\end{tabular}


Table 2: The results of quality test in clove oil soap

\begin{tabular}{lccc}
\hline Analysis & \multirow{2}{*}{ INS } & \multicolumn{2}{c}{ Clove oil } \\
& & $2 \%$ & $3 \%$ \\
\hline Water content & $\max 15.0$ & 1.37 & 1.52 \\
Total fat & $\min 65.0$ & 90.48 & 92.05 \\
Insoluble matter & $\max 5.0$ & 1.26 & 0.80 \\
in ethanol & & & \\
$\begin{array}{l}\text { Free alkali } \\
\text { (as NaOH) }\end{array}$ & $\max 0.1$ & 0.0066 & 0.0053 \\
$\begin{array}{l}\text { Chloride content } \\
\text { Unsaponifiable }\end{array}$ & $\max 1.0$ & 1.17 & 1.17 \\
matter & $\max 0.5$ & 0.032 & 0.003 \\
\hline
\end{tabular}

The quality test of the solid soap as presented in Table 2 revealed that the water content, total fat, free alkali, unsaponifiable matter content and insoluble matter in ethanol have all met the standard set of INS. The chloride content in the synthetic soap was higher than that in the standard due to the high content of chloride in the aquadest that used to make a $\mathrm{NaOH}$ solution. The effect of clove oil on the water content standard shows that the higher the concentration of clove oil in the soap results in, the higher its water content. This is likely caused by the water content in clove oil.

The concentration of clove oil in the soap also affects the free alkali content. The higher the concentration of clove oil results in the smaller the free alkali. This occurs because in the basic condition (alkali) eugenol as the main content of clove oil may react into isoeugenol 24 , thus causing the rest of the free alkali reduced. From the quality test, it can be concluded that in terms of the content of free alkali, the soap samples have all met the INS, being much less than $0.1 \%$.

The INS for a proper soap requires the product to have a total fat at a minimum of $65 \%$. In this work, the data shows that the total fat in $2 \%$ and $3 \%$ clove soaps were found to be $90.48 \%$ and $92.05 \%$, being more than the minimum standard of INS (65\%). In addition to that, all samples contained total fat more than $65 \%$, and thus satisfying the INS, while the additional ingredient other than fat did not result in the content to be more than standard value, which is a maximum of $35 \%$.

Lastly, the clove oil soap also satisfied the INS requirement of having no more than 5\% of insoluble substance in ethanol. As ethanol and clove oil are both polar compounds, they dissolve in each other, following "like dissolves like" rule. In conclusion, the insoluble substance in ethanol is not affected by the addition of clove oil, and in regards to the insoluble substance in ethanol, all samples have fulfilled the INS requirements.

\section{Antibacterial activity test}

Previous research has shown that the use of triclosan in antibacterial soaps lack of health benefit than regular soap. Therefore, in this study used clove oil as a natural antibacterial agent ${ }^{25}$. Clove (Syzygium aromaticum) has been shown to act as an antibacterial agent against Staphylococcus aureus and Escherichia coli ${ }^{26}$. The use of clove oil for antibacterial agents is expected to increase economic value, minimize side effects, and can reduce the risk of resistance.

The detailed results of antibacterial activity tests are presented in Tables 3, 4 and 5. In general, the result showed the growth inhibition on the three bacteria for all treatments. Antibacterial compound was diffused into the media in order to prevent the growth around the paper disc and to form the inhibition zone. All experiments used three discs and performed in triplicate round Fig. 5. It was shown that the larger the diameter of the inhibition zone, the bigger the inhibition power of the compund. According to NCLSS ${ }^{22}$, there are three criteria for the inhibition zone width, i.e. susceptible $(\geq 21 \mathrm{~mm})$, moderate $(17-20 \mathrm{~mm})$, and resistant $(\leq 16 \mathrm{~mm})$. The positive control of chloramphenicol (10 ppm) was found to inhibit the bacteria growth. On the other hand, the three bacteria were still alive when exposed to the aquadest (negative control).

The results of factorial analysis showed that there was no interaction between the combination of clove oil treatment and soap concentration on the inhibitory zone diameter of the Staphylococcus aureus ATCC 25923, which is evidenced by the significance value of $\mathrm{P}>0.05$ (0.975). The diameter of the inhibition zone in the growth of Staphylococcus aureus ATCC 25923 was measured during the $48 \mathrm{~h}$ incubation period. As the inhibition zone did not change after $40 \mathrm{~h}$ incubation period, the data presented were recorded at hour $6^{\text {th }}, 12^{\text {th }}, 24^{\text {th }}, 30^{\text {th }}$, and $36^{\text {th }}$ Table 3 of the observation. The inhibition zone clearly decreased along with the longer 
incubation period. The level of concentration did not necessarily affect the average of diameter of inhibition zone. The positive control (chloramphenicol
$10 \mathrm{ppm}$ ) was successful in inhibiting the growth of $S$. aureus ATCC 25923, while the negative control (aquadest) was not.

Table 3: Diameter of inhibition zone in solid soap combined with clove oils against Staphylococcus aureus ATCC 25923 (mm)

\begin{tabular}{ccccccc}
\hline Clove oil (\%) & Concentration & \multicolumn{5}{c}{ Diameter of inhibition zone observed after (hours) } \\
& of soap (\%) & 6 & 12 & 24 & 30 & 36 \\
\hline \multirow{2}{*}{2} & 2.5 & 26.22 & 16.71 & 17.84 & 16.47 & 7.68 \\
& 5.0 & 18.88 & 14.86 & 14.66 & 13.49 & 9.60 \\
& 7.5 & 19.42 & 15.07 & 14.84 & 15.01 & 11.78 \\
3 & 10 & 17.21 & 16.03 & 15.84 & 15.48 & 12.16 \\
& 2.5 & 43.63 & 17.12 & 16.31 & 8.20 & 7.98 \\
& 5.0 & 19.18 & 16.48 & 15.32 & 9.03 & 9.10 \\
& 7.5 & 21.30 & 17.78 & 17.44 & 7.70 & 8.43 \\
chloramphenicole & 10 & 22.98 & 17.32 & 16.73 & 8.78 & 8.73 \\
aquadest & 10 ppm & 26.64 & 14.43 & 10.86 & 10.08 & 8.40 \\
\hline
\end{tabular}

Table 4: Diameter of inhibition zone in solid soap combined with clove oils against Staphylococcus epidermidisFNCC 0048(mm)

\begin{tabular}{cccccccc}
\hline Clove oil (\%) & $\begin{array}{c}\text { Concentration } \\
\text { of soap (\%) }\end{array}$ & 6 & 12 & 24 & 30 & 36 & 48 \\
\hline 2 & 2.5 & 11.08 & 11.21 & 10.24 & 9.84 & 9.53 & 9.24 \\
& 5.0 & 14.33 & 15.08 & 13.98 & 12.22 & 11.87 & 9.77 \\
& 7.5 & 15.31 & 14.84 & 10.32 & 9.36 & 9.18 & 8.25 \\
3 & 10 & 17.12 & 19.39 & 17.74 & 17.34 & 16.55 & 16.41 \\
& 2.5 & 12.77 & 13.23 & 10.77 & 10.02 & 9.54 & 9.91 \\
& 5.0 & 18.67 & 17.60 & 13.84 & 13.17 & 12.26 & 11.60 \\
& 7.5 & 20.66 & 20.18 & 14.82 & 13.93 & 12.93 & 11.05 \\
& 10 & 19.94 & 22.28 & 17.04 & 15.68 & 14.08 & 13.12 \\
chloramphenicole & 10 ppm & 10.39 & 8.62 & 8.60 & 8.07 & 8.02 & 6.76 \\
aquadest & & 0 & 0 & 0 & 0 & 0 & 0 \\
\hline
\end{tabular}

Table 5: Diameter of the inhibition zone in solid soap combined with clove oils against Eschericia Coli ATCC 11229(mm)

\begin{tabular}{ccccc}
\hline Clove oil (\%) & $\begin{array}{c}\text { Concentration } \\
\text { of soap (\%) }\end{array}$ & $\begin{array}{r}\text { Diameter of } \\
\text { inhibition zone observed after (hours) }\end{array}$ & \multicolumn{2}{c}{ in } \\
\hline 2 & 2.5 & 0 & 0 & 0 \\
& 5.0 & 8.84 & 8.93 & 8.32 \\
& 7.5 & 18.44 & 16.98 & 16.67 \\
3 & 10 & 18.22 & 16.93 & 15.16 \\
& 2.5 & 19.95 & 19.18 & 17.46 \\
& 5.0 & 20.99 & 21.28 & 19.24 \\
& 7.5 & 21.56 & 20.62 & 11.56 \\
chloramphenicol & 10 & 21.22 & 22.18 & 21.33 \\
aquadest & 10 ppm & 14.27 & 13.38 & 12.29 \\
\hline
\end{tabular}




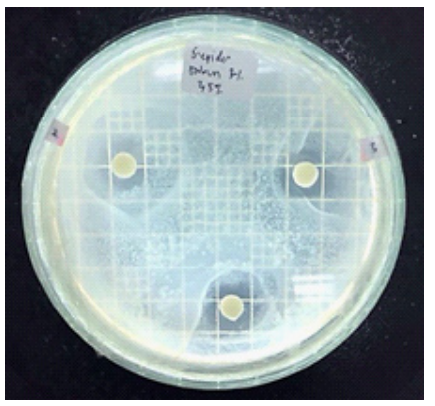

(1)

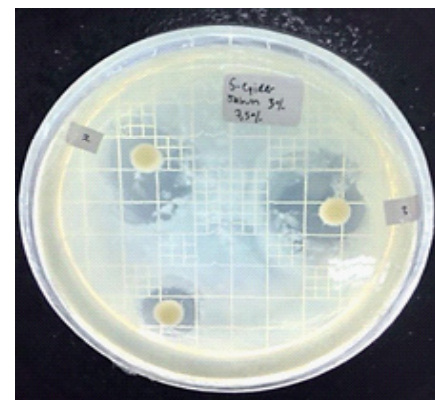

(3)

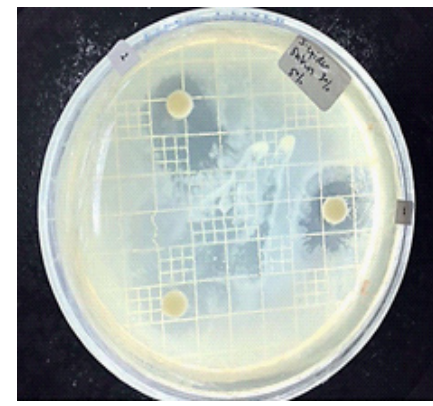

(2)

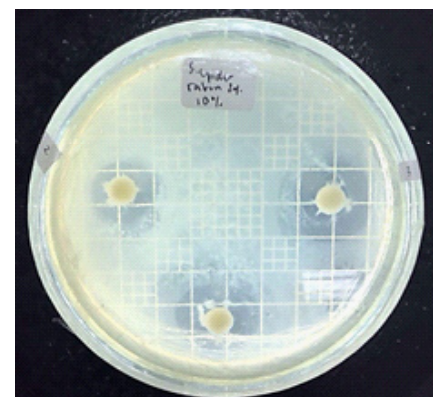

(4)

Fig. 5. Screening of antibacterial activity of soap combined with $3 \%$ of clove oil was performed using Kirby-Bauer test following the agar diffusion method ( $1=2.5 \%$ of soap; $2=5 \%$ of soap; $3=7.5 \%$ of soap; $4=10 \%$ of soap)

Table 3 shows that the inhibition zone at hour $6^{\text {th }}$ was higher than that at the other hours $\left(12^{\text {th }}\right.$, $24^{\text {th }}, 30^{\text {th }}$, and $36^{\text {th }}$ ) on all treatments. The treatment of $3 \%$ clove oil and $2.5 \%$ concentration within $6 \mathrm{~h}$ incubation period showed the highest inhibition zone, and was categorized as susceptible. The use of $3 \%$ concentration of clove oil showed a higher inhibition zone at $24 \mathrm{~h}$ incubation period, although after which, it decreased to the point to be lower than the inhibition zone observed for the $2 \%$ concentration.

The diameter of the inhibition zone in the growth of Staphylococcus epidermidis FNCC 0048 measured during the $48 \mathrm{~h}$ incubation period Table 4 was categorized as moderate $(17-20 \mathrm{~mm})$, and resistant $(\leq 16 \mathrm{~mm})$. It was found that the inhibition zone decreased more along with the longer incubation period. The level of treatment concetration did not necessarily affect the average of the diameter of inhibition zone. Positive control (chloramphenicol $10 \mathrm{ppm}$ ) was successful in inhibiting the growth of S. epidermidis FNCC 0048, while the negative control (aquadest) was not.

Table 4 shows that there was a variation in the levels of inhibition zone between treatments. The highest diameter of inhibition zone was observed at $3 \%$ olive oil treatment, $10 \%$ concentration, and 12 $\mathrm{h}$ incubation period. The $6 \mathrm{~h}$ and $12 \mathrm{~h}$ incubation period was higher compared to others (24-, 30-, 36and $48 \mathrm{~h}$ ). The results of the analysis showed that there was no interaction between the combination of clove oil treatment and soap concentration together with a significance value of $\mathrm{P}>0.05$ (0.097).

The diameter of inhibition zone in the growth of Escherichia coli ATCC 11229 was measured during the $24 \mathrm{~h}$ incubation period as it no longer showed any inhibition at hour 30 Table 5. It is clear that the longer the incubation period showed the more the inhibition zone decreased, while the concentration level of soap treatment did not necessarily increase the average of the diameter of the inhibition zone. Table 5 shows that there was a variation in the levels of inhibition zone between treatments. The results of factorial analysis showed that the combination treatment of clove oil and soap concentration significantly affected the diameter of $E$. coli inhibitory zone, with a significance value of $\mathrm{P}<0.05$ (0.00).

The highest diameter of the inhibition zone was found at $1 \%$ treatment, $2.5 \%$ concentration, and $6 \mathrm{~h}$ incubation period. The $2 \%$ clove oil and $2.5 \%$ concentration treatment did not show any inhibition. Additionally, while the positive control 
(chloramphenicole $10 \mathrm{ppm}$ ) was successful in inhibiting the growth of E.coli ATCC 1129, the negative control (aquadest) was not.

The antibacterial activity test on the three types of bacteria showed that the clove oil concentration had an impact on the antibacterial activity. The highest inhibition zone $(43.63 \mathrm{~mm})$ was found in the soap with $3 \%$ clove oil concentration against Staphylococcus aureusATCC 25923. Meanwhile, the inhibition zones of the antibacterial activities in the soap with $3 \%$ clove oil against Staphylococcus epidermidis FNCC 0048 and Eschericia Coli ATCC 11229 were found to be 22.28 and $22.18 \mathrm{~mm}$, respectively. In conclusion, the addition of $3 \%$ clove oil showed higher antibacterial activity against the three bacteria.

The soap containing triclosan of $0.1 \%$ $-0.45 \% \mathrm{wt} / \mathrm{vol}$ is not more effective than ordinary soap in preventing or reducing bacterial level 25 .
Therefore antibacterial soap from clove oil is better than triclosan.

\section{CONCLUSION}

The quality test of the solid soap revealed that the water content, total fat, free alkali, unsaponifiable matter content and insoluble matter in ethanol have all met the standard set of INS and performs inhibition against all bacteria. Meanwhile, the maximum inhibition zones in the solid soap combined with clove oil (3\%) against Staphylococcus aureus ATCC 25923, Staphylococcus epidermidis FNCC 0048, and Escherichia coli ATCC 11229 were $43.63 \mathrm{~mm}, 22.28 \mathrm{~mm}$, and $22.18 \mathrm{~mm}$, respectively.

\section{ACKNOWLEDGEMENT}

The authors would like to thank DIPAUNY for funding the research, as well as the students for assisting in the laboratory.

\section{REFERENCES}

1. BSN. SNI 3532:2016., 2016.

2. McMurry, J. Organic Chemistry., 2016, 9.

3. Joshi, D.P.; Plainfield, N.J.; Divone, P.A.; Wood haven, N.Y. United States Patent., 1984, 19.

4. Fiss, E.M.; Rule, K.L.; Vikesland, P. J. Environ. Sci. Technol., 2007, 41(7), 2387-2394.

5. Perencevich, E.N.; Wong, M.T.; Harris, A.D. Am. J. Infect. Control., 2001, 29(5), 281-283.

6. Rahimi, R. L. Thesis., 2013.

7. Semilin, V. Thesis., 2014.

8. Asmira, S. Thesis., 2015.

9. Intahphuak, S.; Khonsung, P.; Panthong, A. Pharm. Biol., 2010, 48(2), 151-157.

10. Mutlu, H.; Meier, M.A.R. Eur. J. Lipid. Sci. Technol., 2010, 112, 10-30.

11. Scarpa, A.; Guerci, A. J. Ethnopharmacol., 1982, 5, 117-137.

12. Vieira, C.; Fetzer, S.; Sauer, S.K.; Susanne, K.; Evangelista, S.; Averbeck, B.; Kress, M.; Reeh, P.W.; Cirillo, R.; Lippi, A.; Maggi, C.A.; Manzini, S. Naunyn-Schmiedeberg's Arch. Pharmacol., 2001, 364, 87-95.

13. Pradipto, M. Thesis., 2009.

14. Girgis, A.Y. Grasas y Aceites., 2003, 54(1), 226-233.

15. Baldioli, M.; Servili, M.; Perretti, G.; Montedoro, G.F.; Agrarie, I.; Perugia, U. JAOCS., 1996,
73(11), 1589-1593.

16. Owen, R.W.; Giacosa, A.; Hull, W.E.; Haubner, R.; Spiegelhalder, B.; Bartsch, H. Eur. J. Cancer., 2000, 36, 1235-1247.

17. Muthmainah, R.; Rubiyanto, D.; Yulianto, T.S. Indo. J. Chem. Res., 2014, 1(1), 44-50.

18. Saeed, S.; Tariq, P. Pak. J. Bot., 2008, 4O(5), 2157-2160.

19. Matan, N.; Rimkeeree, H.; Mawson, A.J.; Chompreeda, P.; Haruthaithanasan, V.; Parker, M. Int. J. Food Microbiol., 2006, 107, 180-185.

20. Pramod, K.; Ansari, S.; Ali, J. Nat. Prod. Commun., 2010, 5(12), 1999-2006.

21. Prashar, A.; Locke, I.C.; Evans, C.S. Cell Prolif., 2006, 39, 241-248.

22. Cavalieri, S. J. Manual of Antimicrobial Susceptibility Testing., 2005, 3.

23. Ouedrhiri, W.; Balouiri, M.; Bouhdid, S.; Moja, S.; Chahdi, F.O.; Taleb, M.; Greche, H. Ind. Crop. Prod., 2016, 89, 1-9.

24. Kishore, D.; Kannan, S. Green Chem., 2002, 4, 607-610.

25. Aiello, A.E.; Larson, E.L.; Levy, S.B. Clin. Infect. Dis., 2007, 45(2), S137-S147.

26. Dorman, H.J.D.; Deans, S.G. J. Appl. Microbiol. 2000, 88(2), 308-316. 